\title{
MANAGEMENT AND PRODUCTION CONTROL ISSUES OF DISTRIBUTED ENTERPRISES
}

\author{
George L. Kovács \\ Technical University, Budapest \& University of Pécs \& Computer and Automation Research \\ Institute, Kende u. 13, H-1111 Budapest, Hungary, E-mail: gkovacs@sztaki.hu
}

\begin{abstract}
Enterprises which are distributed in space and/or which are composed as a temporary joint venture of legally different units recently often called virtual (extended) enterprises. Planning, design and operation (management) goals and requirements of such firms are generally different from those of single, centralised enterprises. In this paper we suggest (software) solutions for design, planning and operation of complex, networked organisations represented as nodes of networks. First complex logistics flows of distributed SMEs are targeted, and then an European virtual institute for collaborative demand and supply network will be discussed. The third problem is a complex, web-based solution to manage large, expensive, multi-site, multi-company projects.
\end{abstract}

Key words: extended/virtual enterprise, supply/demand chain, ERP, management, SME.

\section{INTRODUCTION}

Recent manufacturing and service companies are creating "value", not "simply" products. Supply Chain Management (SCM) focuses on globalisation and information management tools, which integrate procurement, operations, and logistics from raw materials to customer satisfaction. Supply chain management is one of the leading business process re-engineering, cost-saving and revenue enhancement strategies in use today. Effective integration of a supply chain can save millions, and more if supply chain strategies are on the table early enough in the product development and design plans.

Please use the following format when citing this chapter:

Kovács, George, L., 2006, in International Federation for Information Processing (IFIP), Volume 207, Knowledge Enterprise: Intelligent Strategies In Product Design, Manufacturing, and Management, eds. K. Wang, Kovacs G., Wozny M., Fang M., (Boston: Springer), pp. 11-20. 
There are some SCM solutions available in the recent market, most of them are for single, centralized organizations and they deal only with restricted tasks, i. e. with management of the supply chain itself. To be able to select the best from different possible solutions a deep analysis and appropriate simulation give a strong assistance.

Today the worldwide globalization and the appearance of virtual enterprises require more than only SCM for some tasks of a given enterprise. Due to the physically and logically distributed character of the co-operating units (workshops, plants, enterprises, etc.), taking advantage of the existence of Internet (www), web-based solutions are suggested.

There are 3 EU projects (FLUENT, WHALES and Co-DESNET, see (Esprit, 1998, 1999 and EU, 2004), which target proper goals. Some issues of these projects will be discussed in this paper.

As today more and more production and service activities are done by extended/virtual enterprises, the result of their activity, the "product" should be understood properly. As the term extended enterprise comprises more than just a single enterprise the term extended product (Jansson, 2002) should comprise more than just the core or tangible product. The EXPIDE (EU, 2003) project works on extending a tangible product. Different services in an intangible shell around the tangible product are defined by means of a layered model. This model shows a type of hierarchical, physical extension of (extended) product services. The concept is three rings around the tangible product. There is a core product that is closely related to the core functions of a product. The second ring describes the packaging of the core functions. The second ring includes only tangible features of the chosen product. The features of the tangible product are different from manufacturer to manufacturer (supplier to supplier). The third ring summarises all the intangible - often intelligent - assets of the product.

\section{MANAGEMENT OF COMPLEX LOGISTIC FLOWS}

New IT solutions are suggested for managing complex logistic flows, occurring in distributed manufacturing networks with multiple plants and cooperating firms. Networks of this kind are gaining relevance and diffusion, under the impulse of the following main factors:

- emerging virtual/extended enterprise paradigms

- pull-oriented production models, like Just-In-Time and Kanban

- lean/agile manufacturing models, based on horizontal, goal-oriented process chains (Hopf, 1994)

- evolving market conditions, calling for business globalisation and decentralisation of manufacturing facilities (Rolstadas, 1994). 

Enterprises

In response to these changes, the newly developed solution and software provide manufacturing firms with advanced IT tools for logistics decisionmaking, thus enhancing their capability to operate in a distributed, networked (virtual, extended) production environment (Kovács, 2003).

Even in a traditional organization where such concepts are neither applied or envisaged, the complexity of logistics decision-making is now increased by factors such as: market globalization, decentralized manufacturing facilities, extended range of suppliers, highest emphasis on total quality issues and customer satisfaction (Hirsch, 1995; Bonfatti, 1996).

In these conditions, traditional logistics functions like sales and purchase are left alone to face problems far beyond their intended roles. Current Enterprise Resource Planning (ERP) systems can be of little help, due to some basic features, which are in conflict with the ERP foundations of:

- Hierarchic organisation,

- Embedding of business processes into the application code,

- Centralized data management based on company-specific standards;

Problems deriving from these evident limitations often induce large companies to assimilate their closest suppliers and sub-contractors, at least from the information system point of view. To overcome these limits, major ERP producers are developing supply-chain management add-ons on top of their production management solutions, often through partnerships with SCP producers. These often imply significant limitations, as:

- Centralized, static planning;

- Manufacturing vs. logistics orientation;

- Pre-defined, hard to adapt organisation model;

- High implementation costs, due to the complexity of SCP integration.

\section{A NOVEL NETWOK/FLOW CONTROL SYSTEM}

Traditional SCM implementations refer to a linear, standardised and relatively stable view of the supply chain: "Supply Chain Management is about managing the flow of products and services and the associated information, across the whole business system to maximise value to the end consumer" (PW, 1997).

The "whole business system" is a row of four to five actors (depending on whether electronic commerce issues are addressed or not) interacting with each other in pairs. The resulting SCM solutions are product suites including several independent tools, each designed to optimize a single link in this pre- 
defined sequence. For the whole picture to work, it is assumed that separate optimization of each link leads to overall performance improvements.

There is a potential failure behind this logic, especially where revenue increase is pursued instead of cost reduction. To look at the supply chain complexity as a competitive advantage, rather than as a source of costs, means a radical change of perspective in the organisation models supported by SCM tools: "For a start, the supply "chain" is really not a chain at all - it is a complicated web of relationships between demand and supply. The concurrent and multidimensional nature of these relationships creates a complex fabric woven step by step (Mirchandani, 1996).

Our solutions capture the inherent complexity of the supply network, allowing firms to manage the three fundamental barriers to supply chain performance improvement: visibility, velocity and variability. This is done by referring to a flexible, scalable and decentralized network model, based on the preservation of nodes' autonomy and on a case-by-case definition of links and dependencies between the nodes. There are supplier-, company-, subcontractor-and customer-nodes in the network. Management is done at knowledge-, planning- and control-level by a Flow Collector (input), Flow Processor (production management) and Flow Dispatcher (output).

Co-operation between nodes is realized through links, each representing a stable relationship for the exchange of a given product between a "supplier" node Flow Collector and a "receiver" node Flow Dispatcher. The Flow Processor is not directly involved in the link, since our flow control is based on a clear separation of logistics decision-making domains. Internal logistics are managed by each node on its own, and are perceived at the network level only through requirements, events and constraints on external logistics flows.

To support the above detailed organisation model, each node is provided with software tools designed to fulfil the requirements of a multi-site, multienterprise manufacturing network, as for example:

-To provide a unified and generalised representation of logistics flows

-To support decentralised and volatile organisation models

-To allow scalable and flexible network configuration

-To support decision-making at the tactical and operational level

-To manage and synchronise multiple decisional processes

-To integrate and distribute relevant information across the network;

-To integrate but not overlap with ERP and other internal-logistics management tools.

To fulfill all goals and requirements we provide an advanced IT infrastructure based on the following software components:

- a standard Communication and Workflow Infrastructure, for basic data interchange and message services.

- a high-level Network Model, on top of this basic layer to have an updated, 
Enterprises

consistent representation of the network from the node point of view;

- an Active Flows Control (AFC) component, which monitors interaction with nodes in the Network Model to maintain updated information;

- a Performance Measurement System (PMS), acting in parallel with the AFC to keep historical records of the network activity;

- two Decision Support Systems (DSS), respectively for input and output flows management, that process internal and external demands; and allow flow planning based on AFC and PMS input,

- an Interface with Enterprise Resource Planning (ERP) that allows transparent interaction with the node local production management.

\section{COLLABORATIVE DEMAND-SUPPLY NETWORKS}

An advanced SCM means a demand network as well. Basically largescale networks of production and service enterprises operating within a common industrial sector are taken into account. The relevant Co-DESNET project (EU, 2004) is devoted to organizing a European Virtual Institute: a permanent network linking all participating partners and other members in the future, based on a vertical web-portal. This portal supplies:

- a Virtual Library of documentations (academic and industrial articles, papers, presentations) concerning supply chains and related topics;

- a Virtual Laboratory of academic and industrial networks (of institutes, companies, SMEs) concerning supply chains and related topics;

- a Virtual Agency of information about conferences and meetings;

- a Discussion Forum for academic and industrial actors.

\section{PROJECT MANAGEMENT ISSUES}

\subsection{Planning, deployment and monitoring}

The objective was to provide a planning and management infrastructure for complex, distributed, multi-site, multi-enterprise organizations working on large scale engineering projects, characterized by huge investments in both materials and human resources and by concurrent, disparate activities (manufacturing, design and services) as well. Managing projects of this kind means dealing with several problems at the same time:

- Complexity of scope, in terms of time and resources employed, and variety 
of activities to be planned, synchronized and monitored;

- Distributed organization, spanning through several companies and involving a multiplicity of actors and competencies;

- One-of-a-kind design, increasing planning complexity, hard to apply product and process standardization;

- Geographic distribution of sites and project activities;

- Strict time constraints, with dangerous critical-path dependencies;

- Contingency risks, due to the high planning uncertainty and difficult realignment of activities;

- Revenue-loss risks, due to difficulties in budgeting and high contingency costs.

Some other projects approach the problem in the following ways:

- Standards and systems are sought for product and process data modelling and interchange, and to support distributed design in concurrent and cooperative engineering environments, see (Esprit, 2000 and 2001).

- Virtual enterprises are studied for the creation of enterprise networks, see (IMS, 2000 and Esprit, 2002).

We focus on the planning and day to day management of (large) projects, assuming that technical departments and engineering functions have proper working tools and standards, and that the conditions for virtual enterprise creation have been fulfilled.

Several managers of the above type projects developed "in house" project databases and project management tools. These systems lack the distributed features and model sophistication. In response to these requirements, our system pursued two main objectives:

- To design and develop a set of software components supporting integrated planning, deployment and monitoring;

- To demonstrate the applicability and benefits of the software components through different pilot business cases.

We implemented the following general features for project management in complex and distributed organizations, the software:

- Provides a unified and generalized representation of project activities and related artefacts, comprising all material and immaterial work items (e.g., products, knowledge, design documents, etc.). Supports distributed organization models, crossing hierarchies and company boundaries.

- Provides a scalable and flexible co-operation environment. The system provides a project network infrastructure accessible to every node.

- Integrates and distributes relevant information across the project network, using a web-based environment.

- Supports decision-making in the project ideation, definition and deployment phases. Takes into account past performance, cost and capabilities to generate detailed plans considering both activities' timing, 
equipment and materials availability, etc.

- Manages and synchronizes the flow of decisions and events in the project network.

- Integrates with local management and planning systems. It means to safeguard the nodes' autonomy and IT investments. The system shall not interfere with node internal procedures and management tools, as ERP, PPC, Human Resources, stand-alone Project Planning and Budgeting packages.

Prime contractors in large-scale projects are typically big companies with proper financial resources and assets. Nevertheless, this does not prevent our system to be extremely significant to SME users that can be involved as nodes (e.g. subcontractors for provision of services and components, to develop entire engineering packages, etc.) in a large project network.

Our project control/management software assists in project planning and deployment thanks to a software infrastructure producing the following measurable results on the end-users' business:

- Improved planning and budgeting; effective contingency management

- Improved monitoring, cost and risk assessment; higher flexibility and efficiency.

\subsection{System software and innovation issues}

To achieve the above improvements requires dealing with different enterprise functions and information sources, supported by heterogeneous and poorly integrated software applications, as:

- Enterprise Resources Planning systems (ERP) (as SAP, Baan, etc.),

- Production Planning and Control (PPC) and Warehousing systems,

- Project planning tools provide graphical editing of GANNT and PERT diagrams, along with display of resources, workload and activities timing,

- Human Resources (HR) packages.

We have a distributed architecture that provides an integrated data and process infrastructure for different companies and actors participating in large projects' planning and execution, at the same time safeguarding each node's autonomy as regards local operations management and information system. These features match key requirements of the "virtual enterprise" organizations working on large one-of-a-kind projects, see (Esprit, 1993a).

The resulting system accommodates the needs of project networks independently of the industrial sector, thanks to its general and adaptable design, that comes from features like:

- Distributed project management environment; Project representation; 
- Decentralized architecture and accountability structure;

- Powerful project and network data model; Flexible decision-support tools.

Three different layers are identified in the network logical architecture. A Network Data Model is closely connected to them:

The Work Network Structure (WNS) constitutes the bottom layer of the system infrastructure, crossing horizontally functional silos at companies cooperating on large scale projects.

The Work Accountability Structure (WAS) constitutes the intermediate layer of the system infrastructure, representing the temporary, multi-site and multi-company organization created to carry out one or more projects.

The Work Breakdown Structure (WBS) corresponds to the topmost layer of the system infrastructure, and represents a network-wise enhancement of WBS implementations supported by traditional Project Planning tools.

To support the outlined organization model the system network is provided with innovative software tools, as:

Web-based Project Environment (WPE). The system architecture is centered on a $W P E-$ an integrated project management infrastructure,

Workflow Management System (WMS). The WPE embeds process automation features provided by a commercial WMS,

Network Data Model (NDM). The system organization model requires a common data infrastructure provided by the NDM - a distributed and decentralized database,

Local Applications Interfaces. Alignment between the new project network management and internal node activities is provided by a set of LAIs,

Decision Support Sub-systems (DSS). Two DSSs are developed and deployed as add-ons to the rest of the software, respectively for:

- Project Planning \& Budgeting to support decision-makers in project ideation and bid preparation tasks,

- Project Monitoring \& Revenue Analysis to support project and site managers in evaluating activities' progress, identifying risk elements and launching contingency actions.

To avoid replication of functionalities and waste of resources, our approach strongly relies on the integration with standard, and commercially available tools. The system is designed and implemented with common tools and principles; see (SCOR, 2001; Jacobson, 1993; Mezgár, 2002 and Horvath, 2004). We apply standards, if possible.

\section{CONCLUSIONS}

The implementation of our logistics flow management/supply chain 
approach represents a significant step forward on state-of-the-art logistics management techniques for the end-users. On the one side, in traditional enterprise practice the focus is on bilateral supply relations with each individual customer and supplier, with scant and informal co-operation possibilities and no supply-chain visibility. On the other side, multi-site planning extensions offered by major ERP and SCP vendors are still based on a centralised approach, lacking on-line integration and synchronisation with the other network actors. In this scenario we provide considerable benefits in terms of improved network visibility, better co-ordination and real-time control of materials flows.

Feasibility of the above improvements, along with the costs and time required for achieving them, are assessed through experimentation of the software system on selected user firms. The validation phase was successfully finished on four pilot cases in different industrial sectors: machine-tool industry, equipment production, textile industry and naval industry. Theoretical issues were discussed to give explanations to the extended products related to extended/virtual production. A new, virtual institute dealing with collaborative demand and supply network was outlined, too.

Experimentation was done on the basic flow management components, supporting network modelling, data-integration and workflow, in parallel with design and development of the decision-support components.

The web-based management software provides a planning and management infrastructure for complex distributed organizations working on large scale engineering projects, characterized by huge investments in both materials and human resources and by concurrent, disparate activities manufacturing, design and services as well.

Four test business cases were co-ordinated dealing with application of common methodologies, metrics and best practices, and ensuring uniformity, comparison and joint evaluation of results produced by each business case:

- shipbuilding and ship-repairing services; - manufacturing plant engineering - software system engineering; - one-of-a-kind manufacturing environment.

The first experiments at all the four different pilot sites have proven all advantages detailed in this paper.

\section{ACKNOWLEDGEMENT}

The author acknowledges the support of the European Union that provided the funds for the research projects FLUENT, Co-DESNET and WHALES the key 
results of which are presented in this paper. We are also thankful for all foreign and Hungarian academic and industrial partners for their cooperation.

\section{REFERENCES}

Bonfatti, F. et al, (1996), Co-ordination Functions in a SME Network. In: Proc. of BASYS '96 International Conference, Lisbon, Chapman \& Hall.

Esprit (1998), FLUENT, Esprit IiM-1998-29088: Flow-oriented Logistics Upgrade for Enterprise NeTworks, EU project documentations.

Esprit (1999), WHALES, ESPRIT IST-1999-12538: Web-linking Heterogeneous Applications for Large-scale Engineering and Services, EU project.

Esprit (1999a), EP 20876 ELSEWISE, Esprit 20876: European LSE Wide Integration Support Effort.

Esprit (2000), EP 20377 OPAL, Esprit 20377, OPAL: Integrated Information and Process Management in Manufacturing Engineering.

Esprit (2001), EP 20408 VEGA, Esprit 20408, VEGA: Virtual Enterprise Using Groupware Tools and Distributed Architecture.

Esprit (2002), EP 26854 VIVE, Esprit 26854, VIVE: Virtual Vertical Enterprise.

EU (2003), EXPIDE, EU Project, http:/www.expide.org.(30.4.2003)

EU (2004), Co-DESNET, EU project, http://www codesnet.polito.it/ (and DoW - not public)

Hirsch, B. E. et al., (1995), Decentralized and collaborative production management in distributed manufacturing environments, Sharing CIME Solutions, IOS Press

Hopf, M.,(1994), Holonic manufacturing systems (HMS) - IMS Test Case 5, in J. H. K. Knudsen et al. (eds), Sharing CIME Solutions, IOS Press.

IMS (2000), IMS GLOBEMAN21, Globeman21 is an IMS project, http://www.ims.org/projects/project_info/globeman.html

Jacobson (1993), OOSE Methodology, Jacobson, I, et al. Object Oriented Software Engineering: a Use Case driven approach, Addison Wesley.

Jansson, K. (2002), Thoben, K-D.: The extended products paradigm, DIISM 2002 - The 5th Int. Conf. on Design of Info. Infrastructure Syst. for Manuf. 2002. Osaka, Japan

Horváth, L. and Rudas, I. J., (2004), Modeling and Problem Solving Methods for Engineers, ISBN 0-12-602250-X, Elsevier, Academic Press.

Kovács, G. L. and Paganelli, P. (2003), A planning and management infrastructure for large, complex distributed projects, Computers in Industry, 51, pp. 165-183.

Mezgar, I., (2002), Communication Infrastructures for Virtual Enterprises, Proc. of the the IFIP World Congress, 31 Aug.- 4 Sept. Vienna/ Budapest, pp. 432-434.

Mirchandani, V. and Block J. (1996), Supply Chain Management and the Back Office, Gartner Group Strategic Analysis Report, September 1996.

PW (1997), Price Waterhouse ${ }^{\complement}$, Supply Chain Management Practice, Supply Chain Planning for Global Supply Chain Management, November 1997.

Rolstadas A. (1994), Beyond Year 2000 - Production Management in the Virtual Company, IFIP Transactions B-19: North Holland 1994.

SCOR (2001), SCOR Model, The Supply Chain Operations Reference-model (SCOR), http://www.supply-chain.org/ 